\title{
Mensaje de bienvenida: ECOS endoscópicos internacionales 2021
}

\author{
Héctor Espino-Cortés \\ Asociación Mexicana de Endoscopia Gastrointestinal y Colegio de Profesionistas, Ciudad de México, México
}

\section{Estimados amigos endoscopistas:}

Como siempre es un gusto poder dirigirme a ustedes, en esta ocasión para presentar el XVIII Curso Ecos Endoscópicos Internacionales, que por segunda vez se transmite en modalidad virtual debido a la pandemia. Decidimos que fuera así dando prioridad a la seguridad de todos, aunque ya muchos quisiéramos vernos personalmente, poder estrechar nuestras manos y abrazarnos, pues cumplimos 16 meses en que se limitaron los eventos presenciales.

Como cada año, Ecos Endoscópicos Internacionales refleja los avances presentados en congresos y cursos de varias partes del mundo, que son revisados por profesores nacionales e internacionales. Agradecemos la disposición de todos ellos para compartir sus conocimientos en las conferencias y sus escritos para este suplemento. Expreso mi agradecimiento a los coordinadores: la Dra. Ma Elena López, Juan Manuel Blancas, Jordán Zamora y Gerardo Blanco. También quiero expresar mi gratitud al personal de la Asociación Mexicana de Endoscopia Gastrointestinal (AMEG), a los amigos de Lahe y especialmente a las casas comerciales que siempre nos apoyan para realizar este curso.
Hemos decidido realizar la reunión nacional de endoscopia de septiembre, en modalidad híbrida, pero con un aforo presencial limitado, cumpliendo con estrictas medidas de seguridad. Todos podrán tomar el curso y congreso por internet. Los que estén interesados en asistir, revisen periódicamente la página de la AMEG para las inscripciones.

Durante esta pandemia hemos tenido una amplia oferta de eventos académicos virtuales, sin embargo, la disminución de las endoscopias realizadas en los centros hospitalarios ha afectado la adquisición de destrezas, principalmente por los endoscopistas jóvenes. En la AMEG estamos preparando las bases para un amplio programa de talleres que permitirá disminuir en algo este problema. Estén pendientes de nuestros mensajes en los siguientes meses.

Por lo pronto, que este curso les sea de mucha utilidad. Les deseo lo mejor a ustedes y sus familias. Cuidémonos mucho, sigamos teniendo las precauciones debidas y recuerden que sus opiniones, sugerencias y participaciones son importantes y bienvenidas. No duden en comunicarse conmigo. Reciban un abrazo fraternal.

Héctor Espino Cortés
Disponible en internet: 12-07-2021

Endoscopia. 2021;33(Supl 1):1 www.endoscopia-ameg.com
Fecha de aceptación: 21-06-2021 DOI: 10.24875/END.M2100035 